GENOMICS

\title{
Sequencing set to alter clinical landscape
}

\section{Access to whole genomes shifts potential for diagnosis, but poses challenges for doctors and regulators.}

\section{BY ERIKA CHECK HAYDEN}

S equencing a patient's complete genome can cost as little as tests that target specific genes, and in a handful of cases it has led to a life-changing diagnosis. No wonder the technology is moving fast from bench to bedside. But as the trend accelerates, researchers are left grappling with complex questions about the medical value of patient genomes, and how sequencing in the clinic should be regulated.

Two clinical sequencing programmes that launched in January, one at Baylor College of Medicine in Houston, Texas, and the other at the University of California, Los Angeles (UCLA), suggest that genomics is about to enter the clinic on a large scale. Already, a growing list of companies and hospitals offer sequencing of whole genomes or the exome (the gene-coding part of the genome). Several other efforts are set to begin this year, and many are in the spotlight this week at the Advances in Genome Biology and Technology meeting in Marco Island, Florida.

"We're all amazed by the speed at which this is happening," says Michael Watson, executive director of the American College of Medical Genetics (ACMG) in Bethesda, Maryland. "I've never seen any genetic technology move at this pace."

Sequencing sets of genes is already being used to guide cancer treatment, and many cancer centres expect to move to whole-genome or exome sequencing at some point. Clinical sequencing programmes aimed at identifying the causes of rare genetic diseases, mostly in children, are also being set up. But how often access to a patient's full genome actually leads to a useful diagnosis is an open question, because most published reports have focused on one-off success stories (see 'Put to the test').

Results from early clinical sequencing efforts are beginning to quantify these successes. Tina Hambuch, scientific liaison at Illumina, based in San Diego, California, which began offering clinical sequencing

$\rightarrow$ NATURE.COM Read more about whole genomes in the clinic at: go.nature.com/yv7rls of UCLA's clinical sequencing programme, says that, so far, about half of the 10 patients who have come through his programme have received a diagnosis. Geneticists caution, however, that these samples are small and highly selective, and that the true rate of

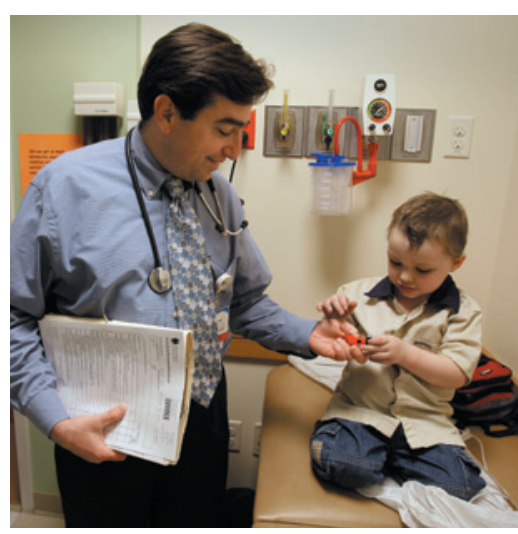

\section{PUT TO THE TEST}

A growing number of successes have spurred the use of whole-genome sequencing as a diagnostic tool.

\section{FEBRUARY 2001 Human genome} draft completed by competing teams.

\section{APRIL 2008 First sequence of an} individual human, James Watson.

\section{MARCH 2010 First sequenced} family uncovers causative gene for Miller syndrome.

JUNE 2010 Doctors help to restore health of Nicholas Volker (pictured) after sequencing indicates that his inflammatory bowel disease could be alleviated by a bone-marrow transplant.

\section{APRIL 2011 Sequencing spares} a woman with leukaemia from undergoing a bone-marrow transplant.

\section{JUNE 2011 Doctors report using} whole-genome sequencing to improve treatment for a patient with the movement disorder dopa-responsive dystonia. diagnosis has yet to be determined.

A further question is cost effectiveness. One speaker at the Marco Island meeting is Heidi Rehm, director of the Laboratory for Molecular Medicine at the Partners HealthCare Center for Personalized Genetic Medicine in Cambridge, Massachusetts. Rehm says that, on a standard test for known hearingrelated genes, about $20 \%$ of the children who come to her clinic with deafness of unknown cause test positive for mutations in the gene that most often causes hearing loss. About the same proportion of the rest test positive for mutations in other hearing-related genes. Yet the standard tests for these sets of mutations can cost thousands of dollars. This means that, at US $\$ 2,500-9,500$, sequencing a complete genome or the exome costs about the same, and so a larger number of patients might obtain a diagnosis.

But interpreting a diagnosis is still no easy matter, because much of the variation in the genome remains poorly understood. "That's the most challenging task we face," says Rehm, who last December received one of six grants awarded by the US National Human Genome Research Institute in Bethesda, Maryland, to explore how clinical sequencing affects health outcomes in a variety of diseases.

In some instances, the diagnosis can lead to a treatment. One of the UCLA patients, for instance, was diagnosed with a rare genetic disease that is treatable by steroids. But such stories are the exception rather than the rule. "I would say a fairly rare percentage of cases are going to be like that," says Hambuch. More often, she says, sequencing reveals a rare and untreatable mutation - information that, although unwelcome, "can save the family and the medical community from doing more testing that isn't going anywhere. If you account for that, then the impact is pretty big."

Deciding what information to give doctors and patients raises its own complex set of questions, such as whether children should be told of their increased risk of an adult-onset disease, and whether doctors who do not reveal such information may later be sued for malpractice. Different clinics approach these questions in different ways. For instance, Illumina is planning to allow patients and their doctors to choose which test results they want to know, and which they do not - for example, whether or not a patient carries the genetic mutation that causes Huntington's disease, an incurable neurodegenerative disorder.

Another area of uncertainty is how regulators will enter into the equation, which could involve oversight of labs, machines, bioinformatics tools and the format of the delivered results. A number of professional groups, including the College of American Pathologists, headquartered in Northfield, Illinois, and the ACMG, are working on guidelines for the field, and some of these will be rolled out this year. - 